\title{
Disastrous Mechanism of Water Discharge in Abandoned Gob above the Stope in Mining Extra-Thick Coal Seam
}

\author{
Haixiao Lin $\left(\mathbb{D},{ }^{1}\right.$ Feng Yang, ${ }^{1}$ Zhengzheng Cao $\mathbb{D}^{1},{ }^{1}$ Yue Wang, ${ }^{1}$ and Xiaojian Jiao ${ }^{1,2}$ \\ ${ }^{1}$ School of Civil Engineering, Henan Polytechnic University, Jiaozuo, 454000 Henan, China \\ ${ }^{2}$ Henan Polytechnic Industrial Technology Research Institute Co. Ltd., Jiaozuo, 454000 Henan, China \\ Correspondence should be addressed to Zhengzheng Cao; caozz@hpu.edu.cn
}

Received 9 January 2021; Revised 7 February 2021; Accepted 20 February 2021; Published 4 March 2021

Academic Editor: Guanglei Zhang

Copyright (c) 2021 Haixiao Lin et al. This is an open access article distributed under the Creative Commons Attribution License, which permits unrestricted use, distribution, and reproduction in any medium, provided the original work is properly cited.

\begin{abstract}
The Datong mining area is a typical double system coal seam mining area in China, where the Jurassic and Carboniferous coal seams are mined simultaneously. The upper Jurassic coal seam has been largely mined, leaving a large amount of gob area. Besides, a large amount of harmful water is accumulated. With the exploitation of the 3-5\# extra-thick coal seam in the Carboniferous system, the scope of overburden damage is greatly increasing, and the mining fracture field is further developed. Once the mining-induced fractures connect with the overlying gob, it is easy to induce the water discharge disaster. With the mining geological conditions of the 8202 working face in the Tongxin coal mine as references, the disastrous mechanism of water discharge in the abandoned gob above the stope in the mining extra-thick coal seam is researched by numerical simulation with the UDEC numerical software, and the research results are obtained. The water in the overlying gob percolates through the mining-induced fractures in the higher key layer forming a "shower" seepage pattern. The water in the above gob converges in the key fracture channel, flowing into the working face. The seepage in the fractures in the high key stratum experiences the process of increase, decrease, and stabilization, related with the stretching and extrusion deformation between the high key stratum blocks. Compared with other fractures, the flow rates in the No.2 and No.4 fractures in the far field key lay are larger, because the fractures are in the tension state, forming the "saddle-shaped" flow pattern. The influencing distance of mining-induced seepage is about $80 \mathrm{~m}$ in front of the working face. The research results provide a guided reference for the prediction and prevention of water discharge disaster in an abandoned gob above the stope in a mining extra-thick coal seam.
\end{abstract}

\section{Introduction}

The Datong coal mining area is a typical dual system of coal seam in China, where the Jurassic and Carboniferous coal seams are mined simultaneously $[1,2]$. At present, the Jurassic coal mining is almost finished, and the Carboniferous 35\# extra-thick coal seam is the key mining zone in the Tongxin mine $[3,4]$. The harmful water in the gob comes from rainfall, rivers, and the overlying aquifer. The mining thickness of the 3-5\# extra-thick coal seam is $14-20 \mathrm{~m}$, which increases the overburden breakage height and fracture development height $[5,6]$. When the fracture filed in the overburden communicates with the mining gob in the upper Jurassic coal seam, the accumulated water in the gob is released to the working face in the Carboniferous 3-5\# extra-thick coal seam, through a mining-induced fracture channel, leading to the water drainage disaster [7-9]. Therefore, it is of great significance to accurately grasp the disastrous mechanism of water discharge in the abandoned gob above the stope in mining the extra-thick coal seam, which provides references for the prevention and control of water drainage disaster.

The significant researches on the disastrous mechanism of water discharge in abandoned gob have been carried out by scholars at home and aboard. Meng [10] determined the cracking connection in the overburden strata above the double system seam mining, with the double system seam mining in the Datong mining area as an engineering background. Du et al. [11] developed the porous medium two-phase watersand flow testing system and researched the influence of sand, the particle sizes of broken rock mass, and the porosity of porous medium on water-sand inrush disaster. Yang et al. [12] built a three field coupled nonlinear flow model based on 
the essentially flow translation, from laminar flow in the aquifer to turbulence flow in the tunnel, in the process of collapsing pillar water inrush. Ju et al. [13] summarized the research progress on the evolution law of mining-induced water conducted zone in overburden, and the waterpreserved mining countermeasures or solutions, according to the theories and practices in water-preserved coal mining under water in China. Hou et al. [14] analyzed the water inrush law with the influencing factors by building an experimental platform and performing a water inrush experiment and established the prediction method for water inrush from ground cracks. Zhang [15] expounded the idea, technical principle, and key technology of water-controlled coal mining technology in detail and solved the problems of large coal resource losses caused by different types of waterproof coal pillar technology in coal mining under a traditional water body. Yang et al. [16] built the overlying rock combination bearing structure model and studied the occurrence mechanism of bedrock fissure conduction working face and water-containing loose layer caused by the cutting-top compression frame of the working face. Zhang et al. [17] analyzed the limit equilibrium conditions of water and sand burst in fractures through the mechanics model of sand body inrush in fractures and carried out the simulation experiments of water and sand burst in fractures under different initial water pressures.

It is obvious that research results of water inrush disaster in the coal mine have been achieved systematically [18-20]. However, the researches on the disastrous mechanism of water discharge in an abandoned gob above the stope in a mining extra-thick coal seam (coal seam thickness is larger than $8 \mathrm{~m}$ ) have been rarely performed. Besides, the mining fracture in the 8202 working face in the Datong mining area is different from the conventional mining situation, since the mining thickness of the 3-5\# extra-thick coal seam is $14-20 \mathrm{~m}$ $[21,22]$. Based on the mining geological conditions at the 8202 working face in the Tongxin mine of the Datong mining area, the disastrous mechanism of water discharge in an abandoned gob above the stope in a mining extra-thick coal seam is studied in this article, by means of numerical simulation with the UDEC numerical calculation software. This study provides a theoretical basis for the prediction and prevention of the water discharge disaster in an abandoned gob above the stope in a mining extra-thick coal seam.

\section{Numerical Calculation Model of Water Discharge Disaster}

UDEC (Universal Distinct Element Code) is the numerical calculation program based on the theory of the discrete element method $[23,24]$. According to the mining geological conditions in the 8202 working face of the Tongxin coal mine, the mining height of the upper Jurassic 14\# coal is $4 \mathrm{~m}$, while that of the lower Carboniferous 3-5\# coal seam is $15 \mathrm{~m}$; besides, the average distance between the two coal seams is $160 \mathrm{~m}$, and the buried depth of 3-5\# coal seam is $480 \mathrm{~m}$. The key point in the numerical calculation is to study the relationship between the fracture of the key layer and the evolution law of the seepage field with the mining of the 3-5\# coal seam. The numerical calculation model has the length of $500 \mathrm{~m}$, the height of $194 \mathrm{~m}$, and the mining depth of $488 \mathrm{~m}$. The numerical model is shown in Figure 1.

The boundary condition of both sides is the velocity boundary condition, the horizontal direction is fixed, and the bottom boundary of the model is fixed in the vertical direction. Besides, the vertical stress on the upper boundary is $8.6 \mathrm{MPa}$, which is the converted by the overburden on the upper part of the model. Both the sides and bottom of the model are set as the impermeable boundary, that is, there is no water supply, but seepage pressure exchange can be carried out at this boundary. The top of the model has a free boundary that can be supplied from the top according to changes in water pressure. When the $14 \#$ coal seam is being mined, the hydraulic boundary is applied in the way of fixed water pressure. After the mining of the 3-5\# coal seam, the water pressure in the gob is set as zero. When the harmful water enters the space, the pressure is set as zero. Besides, the physical parameters of the rock mass are shown in Table 1, and the percolation mechanical parameters of joints are shown in Table 2. The data for the numerical calculation in Tables 1 and 2 are obtained by the rock mechanics experiments.

Therefore, the numerical calculation scheme is determined. In the numerical calculation, the $14 \#$ coal seam is firstly mined, and the mining width is $300 \mathrm{~m}$, with $100 \mathrm{~m}$ pillars on both sides left to eliminate the boundary effect. The mining width of the $3-5 \#$ coal seam is $300 \mathrm{~m}$, with $15 \mathrm{~m}$ each step, when the mining of the $14 \#$ coal seam is finished, and the development law of the overburden fracture and seepage field is analyzed.

\section{Spatial and Temporal Evolution Law of Water Discharge Disaster}

After the 14\# coal seam is mined, the water pressure distribution of the overburden in initial equilibrium is shown in Figure 2, when the water pressure in the gob is $0.1 \mathrm{MPa}$ before the mining of the $14 \#$ coal seam. It is indicated that the pore pressure of the surrounding rock in the middle of the mining gob is bigger, and that in both ends is smaller. The key layer refers to the strata which control the whole or partial overburden movement from the overburden to the surface [25].

When the 8202 working face in the $3-5 \#$ coal seam advances to $30 \mathrm{~m}$, the initial caving of the direct roof occurs, and the transverse cracks on the top rapidly develop to the bottom of key layer 1. The pore pressure in the top of key layer 3 (far field key layer) is the maximum value $0.3183 \mathrm{MPa}$. The maximum pore pressure of the roof in the unexploited area in the $3-5 \#$ coal seam is $0.2929 \mathrm{MPa}$, as shown in Figure 3. From the perspective of flow velocity distribution, the water flow in the floor at both ends is the largest, with a maximum of $0.78 \mathrm{~m}^{3} / \mathrm{s}$, since both ends of the gob of the 14\# coal mine have the maximum fracture depth and fracture opening degree. It is located within $1 \mathrm{~m}$ below the floor at both ends, and the flow outside $1 \mathrm{~m}$ below the floor drops to $1.4 \times 10^{-6} \mathrm{~m}^{3} / \mathrm{s}$ rapidly, with a great change in 


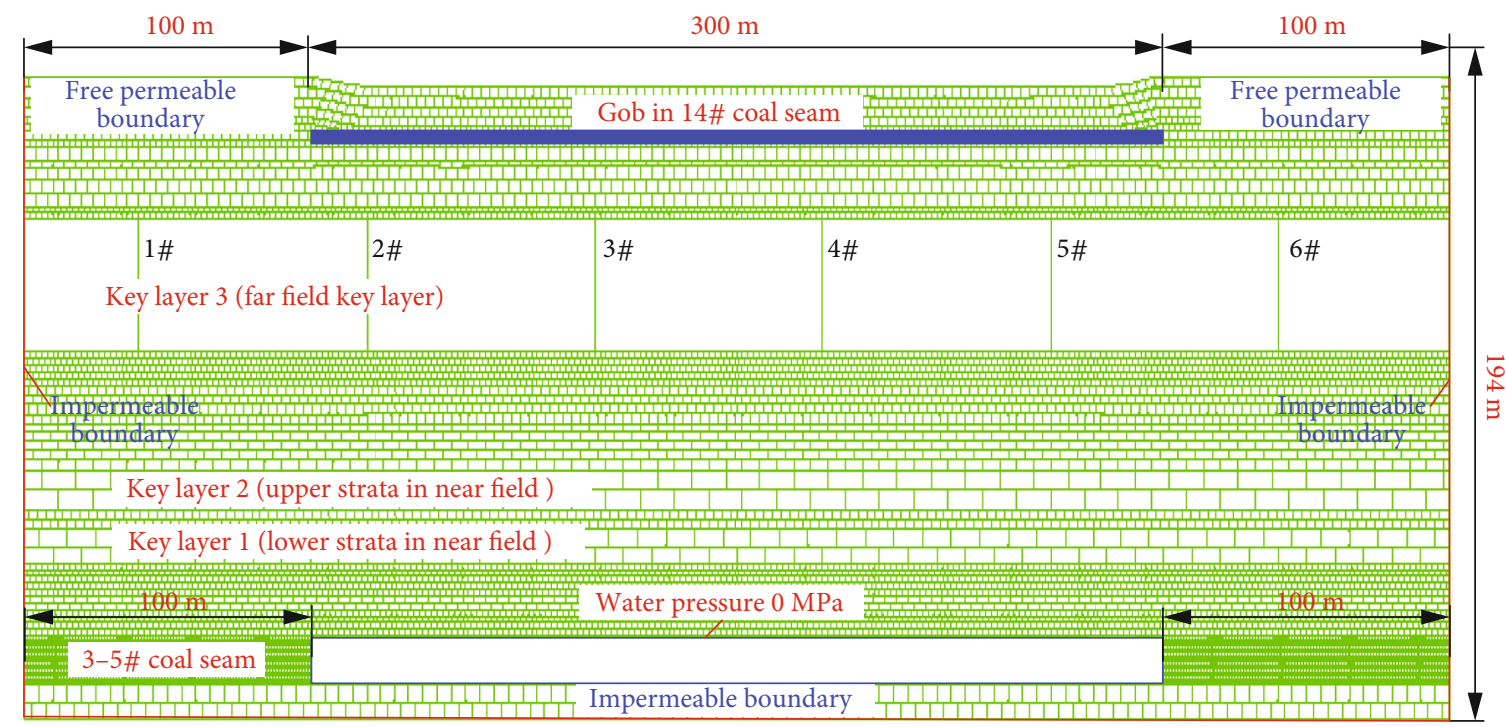

FIgURE 1: The numerical calculation model.

TABLe 1: The physical parameters of rock mass.

\begin{tabular}{|c|c|c|c|c|c|c|}
\hline Rock strata & $\begin{array}{c}K \\
(\mathrm{GPa})\end{array}$ & $\begin{array}{c}G \\
(\mathrm{GPa})\end{array}$ & $\begin{array}{c}d\left(\mathrm{~N} \cdot \mathrm{m}^{-}\right. \\
3)\end{array}$ & $\begin{array}{c}f \\
\left({ }^{\circ}\right)\end{array}$ & $\begin{array}{c}C \\
(\mathrm{MPa})\end{array}$ & $\begin{array}{c}t \\
(\mathrm{MPa})\end{array}$ \\
\hline Coal seam & 3.89 & 1.59 & 1426 & 42 & 2.01 & 1.6 \\
\hline $\begin{array}{l}\text { Sandy } \\
\text { mudstone }\end{array}$ & 30.35 & 14.74 & 2693 & 35 & 12.5 & 4.4 \\
\hline Siltstone & 18.50 & 16.02 & 2604 & 34 & 4.8 & 4.89 \\
\hline Fine sandstone & 19.79 & 19.86 & 2700 & 34 & 4.8 & 6.4 \\
\hline $\begin{array}{l}\text { Medium } \\
\text { sandstone }\end{array}$ & 23.24 & 15.93 & 2654 & 35 & 12.5 & 5.72 \\
\hline $\begin{array}{l}\text { Coarse } \\
\text { sandstone }\end{array}$ & 10.85 & 7.5 & 2540 & 35 & 12.5 & 2.56 \\
\hline
\end{tabular}

TABLE 2: The percolation mechanical parameters of joints.

\begin{tabular}{lcccc}
\hline Rock strata & $f\left(^{\circ}\right)$ & jperm $\left(\mathrm{Pa}^{-1} \cdot \mathrm{s}^{-1}\right)$ & azero $(\mathrm{m})$ & ares $(\mathrm{m})$ \\
\hline Coal seam & 30 & 83 & 0.0001 & 0.00001 \\
Sandy mudstone & 32 & 100 & 0.0001 & 0.00001 \\
Siltstone & 30 & 128 & 0.0002 & 0.00003 \\
Fine sandstone & 30 & 143 & 0.0003 & 0.00004 \\
Medium sandstone & 33 & 178 & 0.0002 & 0.00003 \\
Coarse sandstone & 32 & 246 & 0.0004 & 0.00006 \\
\hline
\end{tabular}

magnitude. At the same time, it is also noted that prefabricated primary joints in the key layer 3 (far key layer) also have the seepage phenomenon, but the flow rate is $2.472 \times$ $10^{-8} \mathrm{~m}^{3} / \mathrm{s}$, with the extremely low seepage flow. In addition, the maximum flow rate in the roof of the $3-5 \#$ coal seam is $5.553 \times 10^{-8} \mathrm{~m}^{3} / \mathrm{s}$, and it is located at $7 \mathrm{~m}$ in the direct roof, which is derived from the extremely low seepage generated through the primary fracture, as shown in Figure 4. According to the flow velocity vector distribution in the initial caving of the direct roof, the flow not only percolates downward along the longitudinal fracture but also percolates along the transverse fracture, and the flow confluence or separation occurs at a node, as shown in Figure 5.

When the 8202 working face in the $3-5 \#$ coal seam advances to $90 \mathrm{~m}$, the initial caving of key layer 1 occurs. Because the key layer 1 is $22 \mathrm{~m}$ away from the top plate of the 3-5\# coal seam, the rock layer cannot form a stable structure, so it collapses into the gob with revolving instability and becomes part of the caving zone. The distance between the key layer 1 and the key layer 2 is only $6 \mathrm{~m}$. The overburden movement deformation caused by the fracture of the key layer 1 has a significant impact on the key layer 2 and its upper layers, resulting in obvious longitudinal and transverse fractures in the key layer 2. At the same time, due to the breakage of key layer 1, the maximum pore pressure in the mining area increases to $0.3909 \mathrm{MPa}$, as shown in Figure 6. The flow distribution in the initial caving of key layer 1 is obtained. The fractures in the overburden above the key layer 1 develop further, and water in the gob penetrates downward through primary fractures in key layer 3 (far field key layer) at a small flow rate and enters the key seepage channel of the working face. The flow rate in the key layer 3 (far field key layer) increases to $5.374 \times 10^{-8} \mathrm{~m}^{3} / \mathrm{s}$, and the maximum flow rate in the working face reaches $5.374 \times 10^{-8} \mathrm{~m}^{3} / \mathrm{s}$, which increases by nearly 10 times, as shown in Figure 7. According to the flow velocity vector distribution in the initial caving of key layer 1, as shown in Figure 8, the water in the far field key layer in the primary joint seepage phenomenon begins to appear, along with the increase of the fracture opening in key layer 3. Besides, the phenomenon of the water seepage in the lower rock layer is more obvious in the primary joint with a large opening, and the water seepage is concentrated in the gob.

When the 8202 working face in the $3-5 \#$ coal seam advances to $120 \mathrm{~m}$, the initial caving of key layer 2 occurs. Because the key layer 2 is $37 \mathrm{~m}$ away from the top plate of the 3-5\# coal seam, the rock layer cannot form a stable 


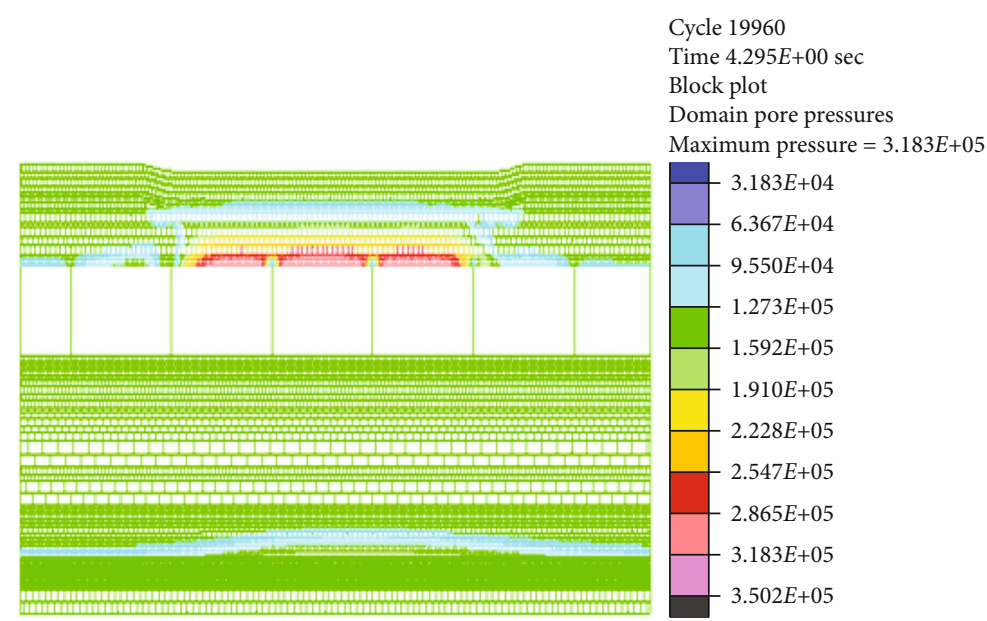

Figure 2: The water pressure distribution in initial equilibrium.

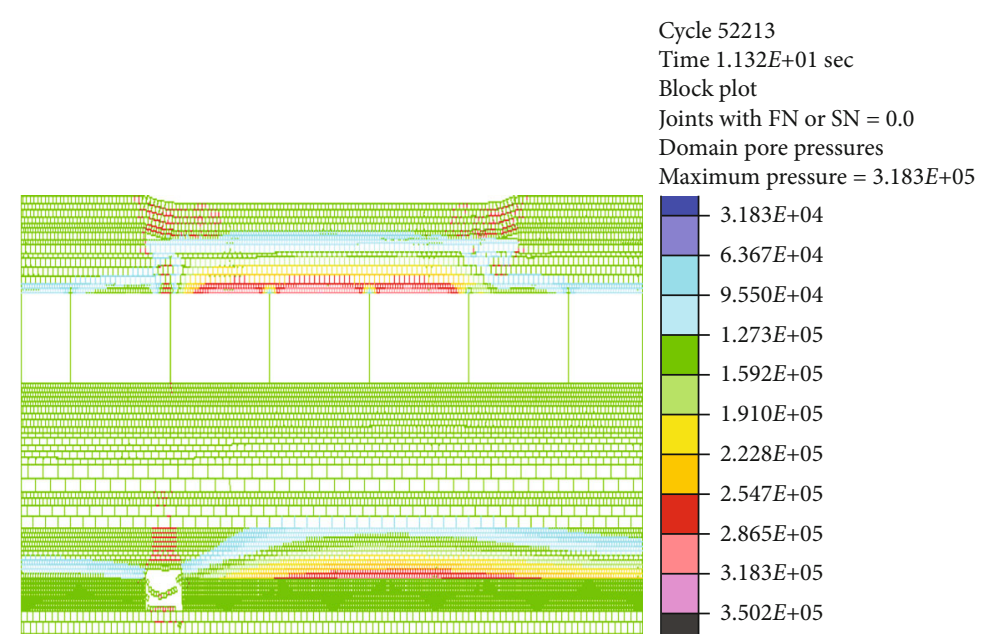

FIgURE 3: The pore pressure distribution in initial caving of direct roof.

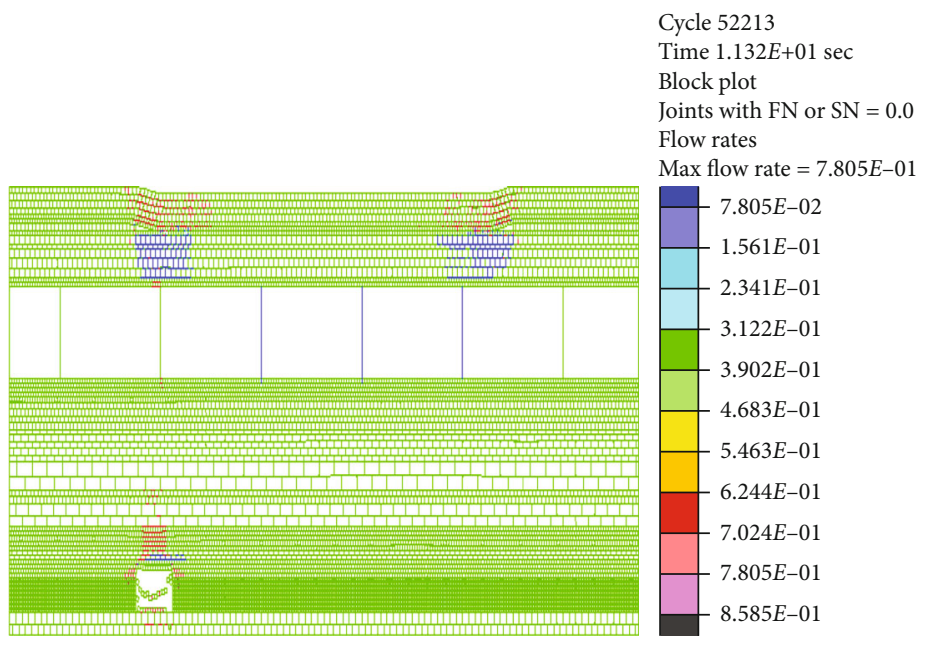

FIgURE 4: The flow distribution in initial caving of direct roof.

structure, so it caves into the gob and becomes part of the caving zone. After the breakage of key layer 2, tensile fractures appear in the lower part of key layer 3 (far field key layer) above the central position of the gob and in the upper part of key layer $3 \mathrm{far}$ from the mining center. Meanwhile, the maximum pore pressure at the top of key layer 3 decreases to 


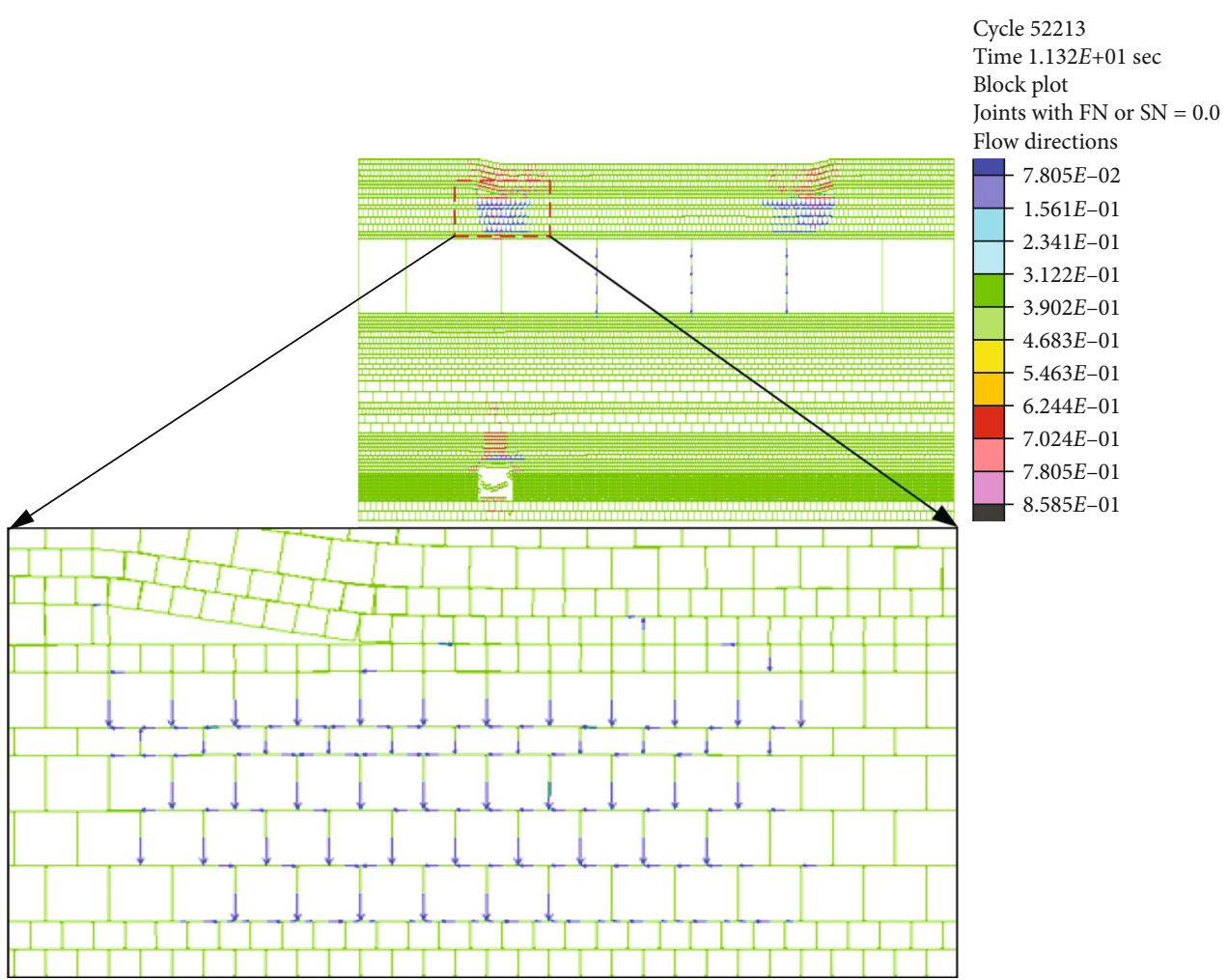

FIgUre 5: The flow velocity vector distribution in initial caving of direct roof.

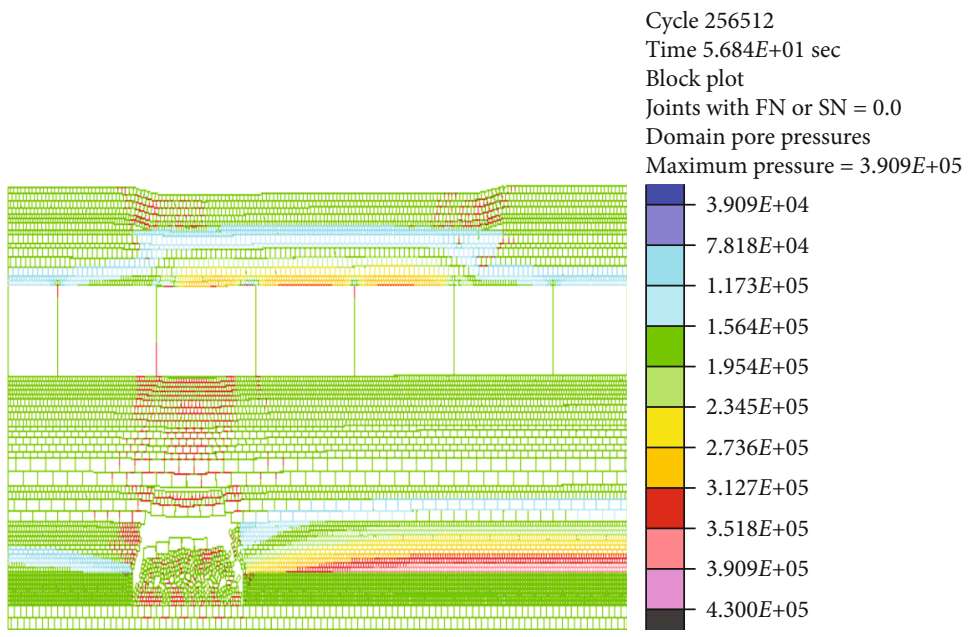

FIGURE 6: The pore pressure distribution in initial caving of key layer 1 .

$0.3174 \mathrm{MPa}$, while the pore pressure in the unexploited area of the coal seam increases to $0.4283 \mathrm{MPa}$, as shown in Figure 9. The flow distribution in the initial caving of key layer 2 is obtained in Figure 10; the water seepage flow of the No.1 fracture in the far field key layer reaches $7.736 \times$ $10^{-8} \mathrm{~m}^{3} / \mathrm{s}$, the No.2 fracture seepage flow is $6.623 \times 10^{-8} \mathrm{~m}^{3}$ $/ \mathrm{s}$, the No.3 fracture seepage flow is $7.071 \times 10^{-8} \mathrm{~m}^{3} / \mathrm{s}$, the No.4 fracture seepage flow is $8.394 \times 10^{-8} \mathrm{~m}^{3} / \mathrm{s}$, and the No. 5 fracture seepage flow is $2.089 \times 10^{-8} \mathrm{~m}^{3} / \mathrm{s}$. The seepage flows in the No.1 and No.4 fractures are greater than those in the No. 2 and No. 3 fractures, affected by mining in advance.
At this time, the maximum flow rate in the 8202 working face reaches $1.224 \times 10^{-3} \mathrm{~m}^{3} / \mathrm{s}$. The flow velocity vector distribution in the initial caving of key layer 2 is obtained in Figure 11. The water flowing velocity increases in the far field key layer, along with the increase of the fracture opening, and the water seepage flows as a "shower" form. The "shower" seepage pattern is the blue line under the far field key layer in Figure 10. Besides, there are water flows along both the longitudinal fractures and the horizontal fractures, and the overall flow direction eventually permeates to the key fracture channel of the gob in the 8202 working face. 


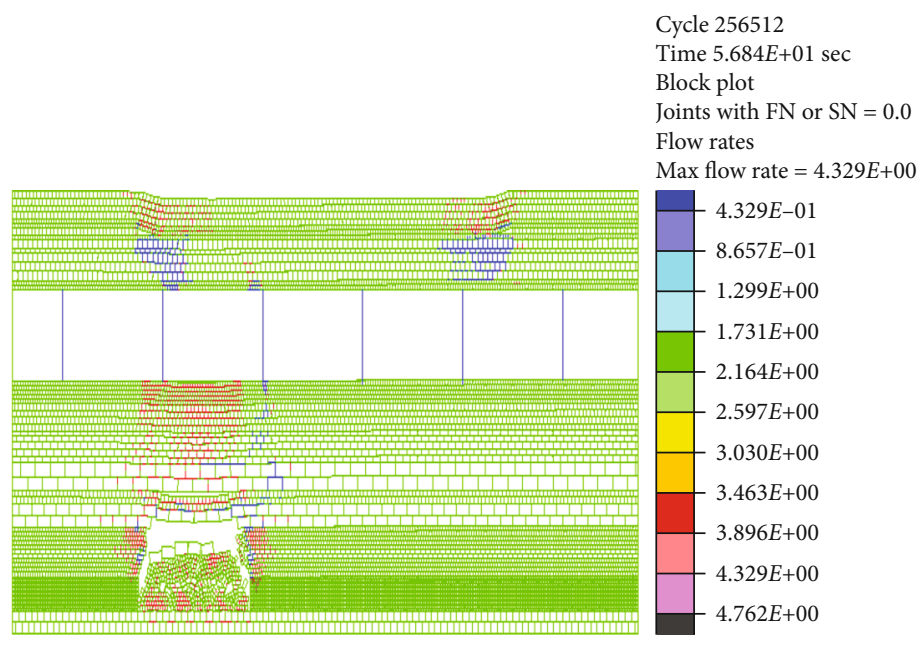

FIGURE 7: The flow distribution in initial caving of key layer 1.

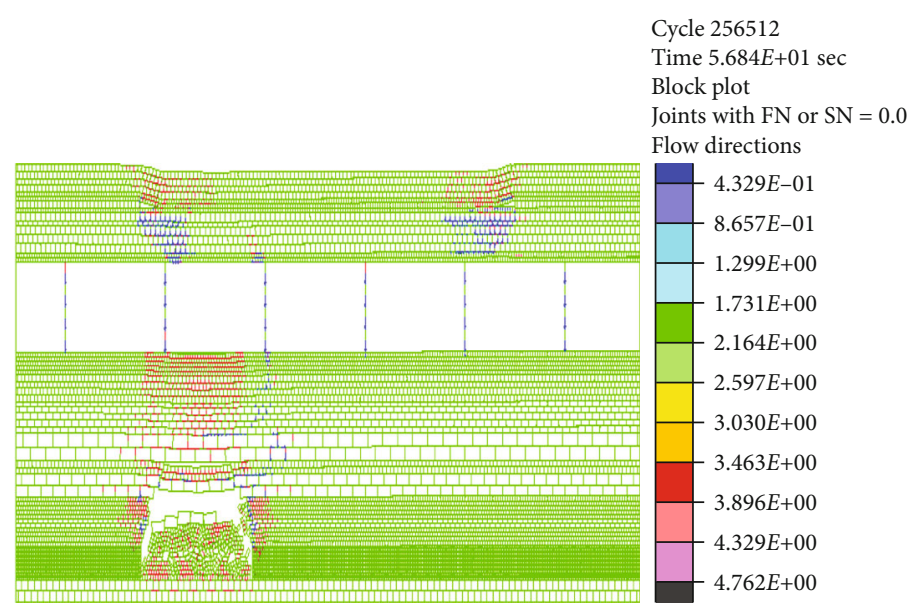

FIgURE 8: The flow velocity vector distribution in initial caving of key layer 1.

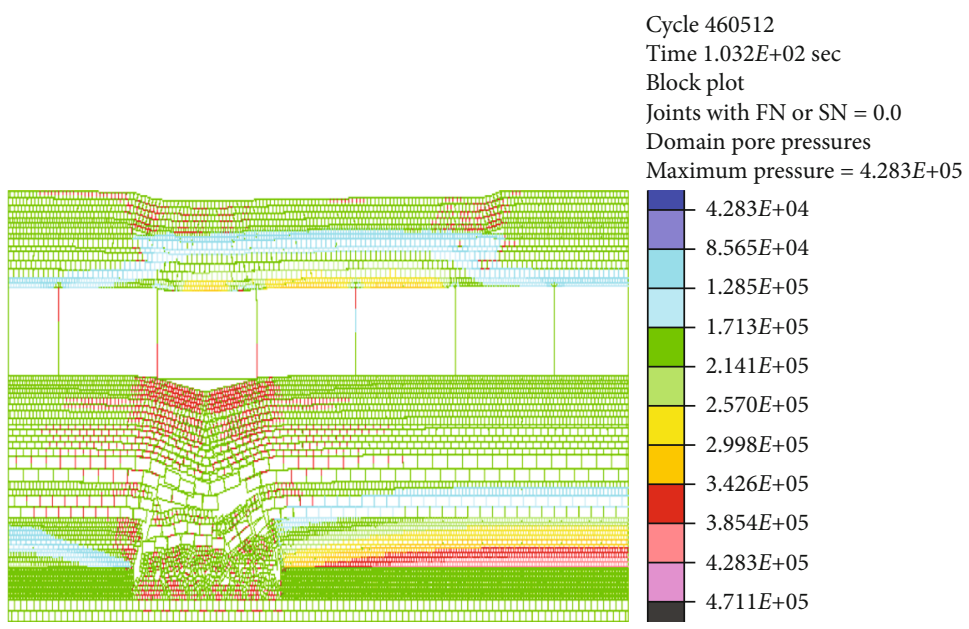

FIGURE 9: The pore pressure distribution in initial caving of key layer 2.

When the 8202 working face in the $3-5 \#$ coal seam advances to $180 \mathrm{~m}$, the initial caving of key layer 3 (far field key layer) occurs, and the key layer 3 forms a stable structure of the voussoir beam. After the breakage of the rock strata, the middle part of the upper rock stratum is in the state of compression, and the fractures appear in the state of interlayer dislocation. The two clamped ends of the voussoir beam in key layer 3 are tensile fractures, which are the key channel 


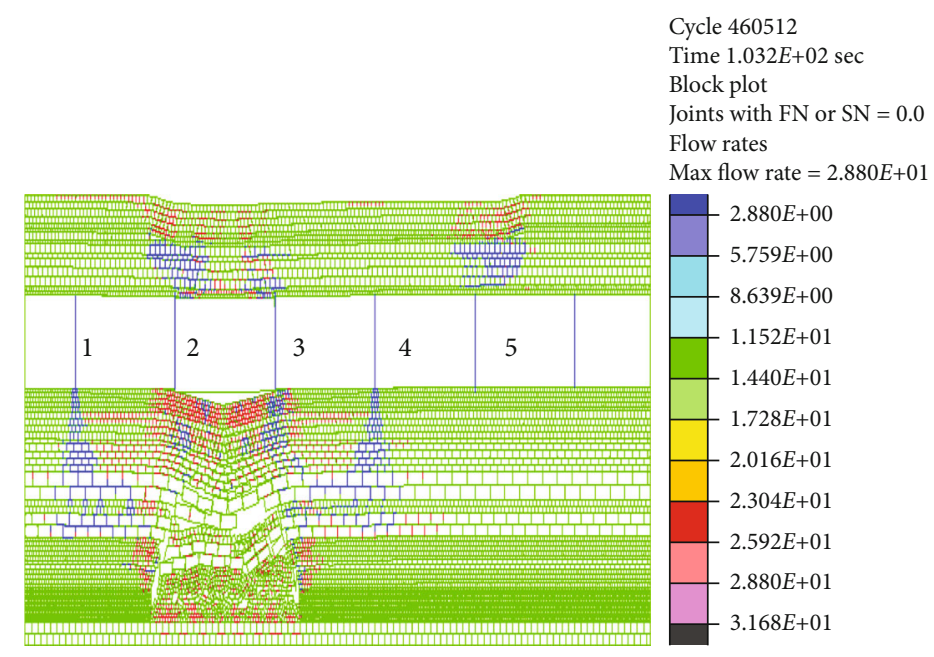

FIgURE 10: The flow distribution in initial caving of key layer 2.

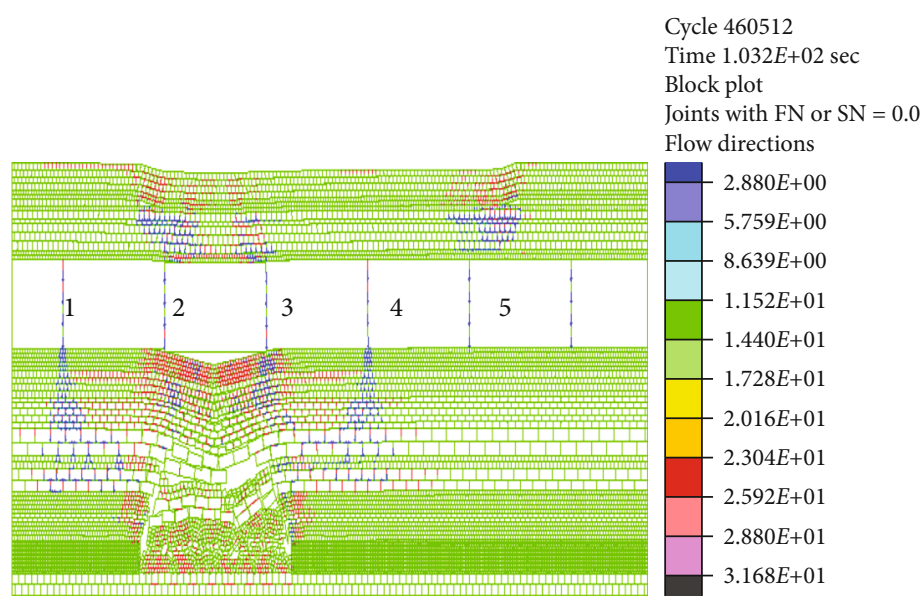

FIGURE 11: The flow velocity vector distribution in initial caving of key layer 2.

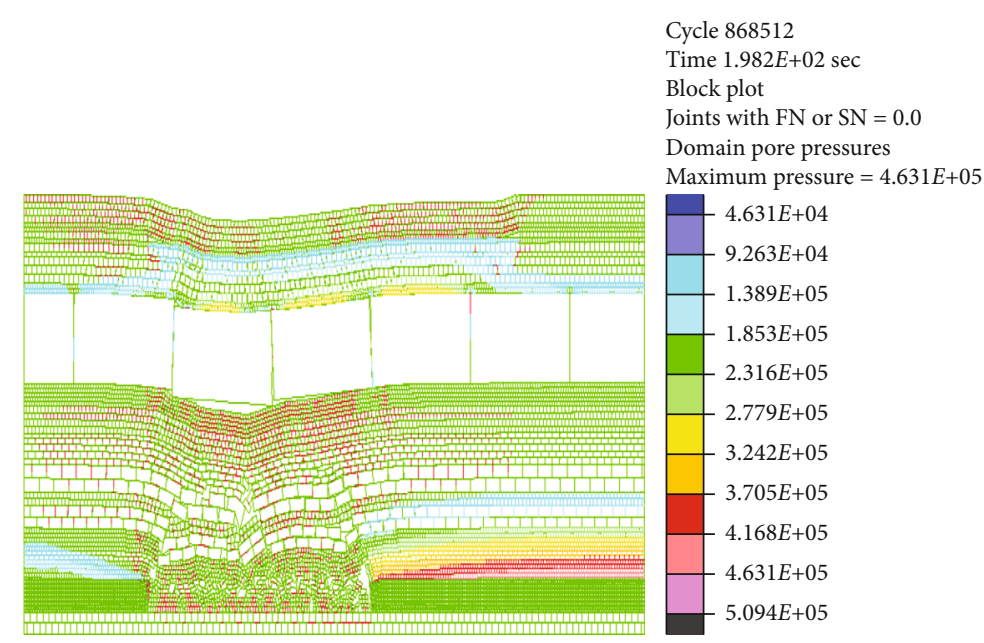

FIGURE 12: The pore pressure distribution in initial caving of key layer 3.

for water flowing into the working face. Besides, the largest pore pressure at the top of key layer 3 slightly reduced to $0.3159 \mathrm{MPa}$, while the pore pressure in the unexploited area of the coal seam increases to $0.4631 \mathrm{MPa}$, as shown in Figure 12. The flow distribution in the initial caving of key layer 3 is shown in Figure 13. The water seepage flow of the 
Cycle 868512

Time $1.982 E+02 \mathrm{sec}$

Block plot

Joints with $\mathrm{FN}$ or $\mathrm{SN}=0.0$

Flow rates

Max flow rate $=1.488 E+02$

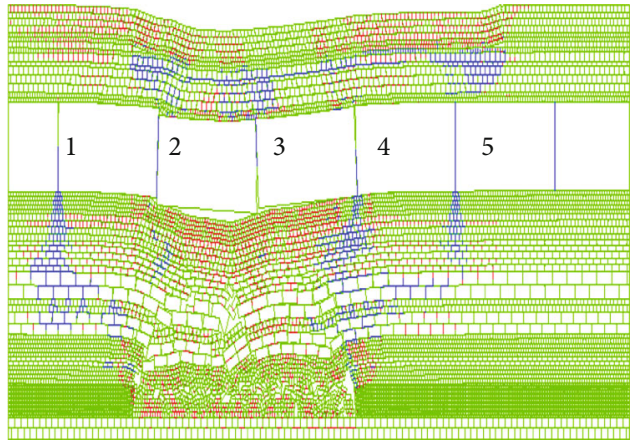

$-1.488 E+01$

$2.976 E+01$

$\begin{array}{r}4.464 E+01 \\ \hline \\ \hline\end{array} .951 E+01$

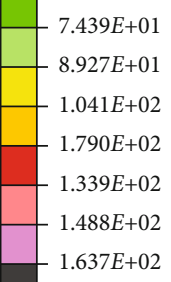

FIgURE 13: The flow distribution in initial caving of key layer 3.

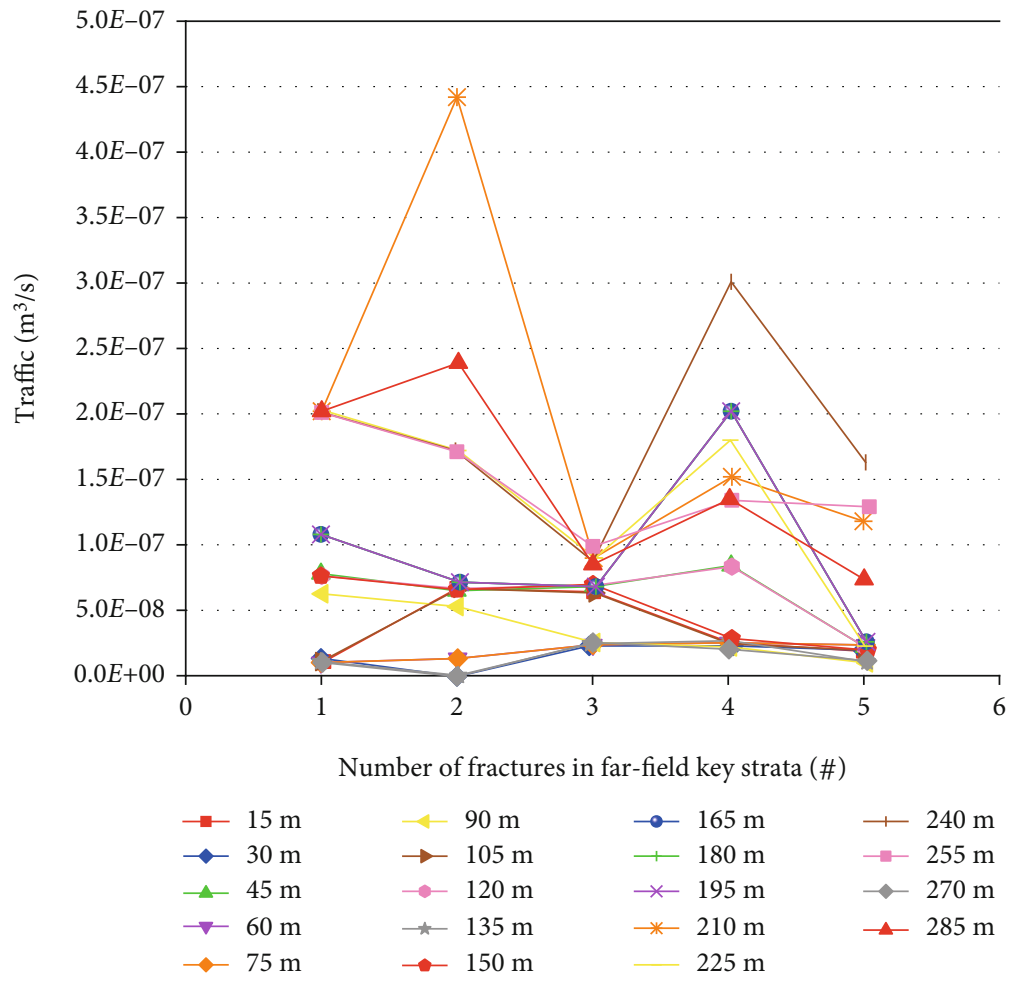

FIGURE 14: The fracture flow distribution curve in key layer 3 (far field key layer).

No.1 fracture in the far field key layer reaches $1.064 \times 10^{-7}$ $\mathrm{m}^{3} / \mathrm{s}$, the No.2 fracture seepage flow reaches $9.598 \times 10^{-8}$ $\mathrm{m}^{3} / \mathrm{s}$, the No.3 fracture seepage flow reaches $6.967 \times 10^{-8}$ $\mathrm{m}^{3} / \mathrm{s}$, the No.4 fracture seepage flow reaches $1.608 \times 10^{-7}$ $\mathrm{m}^{3} / \mathrm{s}$, and the No.5 fracture seepage flow reaches $8.368 \times$ $10^{-8} \mathrm{~m}^{3} / \mathrm{s}$. Meanwhile, the maximum flow in the 8202 working face reaches $2.342 \times 10^{-3} \mathrm{~m}^{3} / \mathrm{s}$.

It is obvious that the development of mining-induced fractures experiences several states of "small-expansionpeak-closure-stable," with the advance of the 8202 working face. The No.1 fracture is located outside of the stope, so the fracture development is in the open state in the whole process. The No.2 fracture is located at $20 \mathrm{~m}$ inside the cut hole, and its seepage velocity is the maximum, which forms the permanent fracture passage. Besides, the influence distance of mining-induced seepage is about $80 \mathrm{~m}$ in front of the working face, and the range of the seepage stability zone is about $165 \mathrm{~m}-265 \mathrm{~m}$ behind the gob.

The fracture flow distribution curve in key layer 3 is obtained in Figure 14. The No.3 fracture is located in the center position of key layer 3 , and the upper part is in the state of compression, which is difficult for the seepage of water in the above gob; therefore, the flow rate in the No.3 fracture is smaller. Compared with other fractures, the flow rates in 
the No.2 and No.4 fractures are larger, because the fractures are in the tension state, forming the "saddle-shaped" flow pattern.

\section{Conclusions}

(1) When the 8202 working face in the $3-5 \#$ coal seam advances to $90 \mathrm{~m}$, the initial caving of key layer 1 occurs, and the rock layer cannot form a stable structure, collapsing into the gob. The water in the overlying gob percolates through the fractures in the higher key layer forming a "shower" seepage pattern. The water in the above gob converges in the key fracture channel and then flows into the working face

(2) When the 8202 working face in the $3-5 \#$ coal seam advances to $120 \mathrm{~m}$, the initial caving of key layer 2 occurs, and the rock layer cannot form a stable structure. The fracture seepage in the high key stratum experiences the process of increase, decrease, and stabilization, which is related with the stretching and extrusion deformation between the high key stratum blocks in the process of working face propulsion

(3) When the 8202 working face in the 3-5\# coal seam advances to $180 \mathrm{~m}$, the initial caving of key layer 3 occurs, and the key layer 3 forms a stable structure of the voussoir beam. The influence distance of the mining-induced seepage is about $80 \mathrm{~m}$ in front of the working face, and the range of the seepage stability zone is about $165 \mathrm{~m}-265 \mathrm{~m}$ behind the gob. Compared with other fractures, the flow rates in the No.2 and No.4 fractures are larger, forming the "saddleshaped" flow pattern

\section{Data Availability}

The data used to support the findings of this study are included within the article.

\section{Conflicts of Interest}

The authors declare that they have no conflicts of interest.

\section{Acknowledgments}

This work was supported by the National Natural Science Foundation of China (52004082), the Natural Science Foundation of Henan Province (202300410170), the Foundation for Higher Education Key Research Project by Henan Province (18A440012), the Ph.D. Programs Foundation of Henan Polytechnic University (B2021-57), the Fundamental Research Funds for the University of Henan Province (NSFRF200302), the Postdoctoral Research Projects of Henan Province, the Scientific and Technological Development Project for Coal Mine Safety Production by Henan Province (HN19-59), the Virtual Simulation Experiment Teaching Project of Henan Province, and the Research and Practice Project of Educational and Teaching Reformation of Henan Polytechnic University (2019JG074).

\section{References}

[1] S. X. Yin, Y. Wang, H. C. Yin et al., "Mechanism and full-timespace prevention and control technology of water inrush from Ordovician and thin limestone in deep mines," Journal of China Coal Society, vol. 45, no. 5, pp. 1855-1864, 2020.

[2] D. Ma, H. Y. Duan, W. T. Liu, X. T. Ma, and M. Tao, "Watersediment two-phase flow inrush hazard in rock fractures of overburden strata during coal mining," Mine Water and the Environment, vol. 39, no. 2, pp. 308-319, 2020.

[3] Y. Xue, P. G. Ranjith, F. N. Dang et al., "Analysis of deformation, permeability and energy evolution characteristics of coal mass around borehole after excavation," Natural Resources Research, vol. 29, no. 5, pp. 3159-3177, 2020.

[4] J. Liu, X. Liang, Y. Xue, K. Yao, and Y. Fu, "Numerical evaluation on multiphase flow and heat transfer during thermal stimulation enhanced shale gas recovery," Applied Thermal Engineering, vol. 178, p. 115554, 2020.

[5] B. H. Yao, J. P. Wei, D. K. Wang, Y. G. Wang, and H. T. Zhang, "A numerically simulated model on the water-inrush risk under the geo-condition of thin rock-mass with thick-loose bed in Sima coal mine," Journal of Safety and Environment, vol. 14, no. 4, pp. 137-141, 2014.

[6] D. Ma, H. Y. Duan, X. B. Li, Z. H. Li, Z. L. Zhou, and T. B. Li, "Effects of seepage-induced erosion on nonlinear hydraulic properties of broken red sandstones," Tunnelling and Underground Space Technology, vol. 91, p. 102993, 2019.

[7] W. L. Shen, J. B. Bai, W. F. Li, and X. Y. Wang, "Prediction of relative displacement for entry roof with weak plane under the effect of mining abutment stress," Tunnelling and Underground Space Technology, vol. 71, pp. 309-317, 2018.

[8] Y. Xue, F. Gao, T. Teng, and Y. Xing, "Effect of gas pressure on rock burst proneness indexes and energy dissipation of coal samples," Geotechnical and Geological Engineering, vol. 34, no. 6, pp. 1737-1748, 2016.

[9] J. T. Chen, L. M. Yi, W. B. Sun, C. Lu, S. C. Zhang, and X. Z. Sun, "Development and application of new deep solid-fluid coupling similar materials," Chinese Journal of Rock Mechanics and Engineering, vol. 34, pp. 3956-3964, 2015.

[10] X. B. Meng, "Safety and high efficient mining technology of ultra thick seam with double system interaction in Datong mining area," Coal Science and Technology, vol. 45, no. 8, pp. 114-120, 2017.

[11] F. Du, Z. H. Li, G. H. Jiang, and Z. Q. Chen, “Types and mechanism of water-sand inrush disaster in west coal mine," Journal of China Coal Society, vol. 42, no. 7, pp. 1846-1853, 2017.

[12] T. H. Yang, W. H. Shi, H. L. Liu, B. Yang, X. Yang, and Z. B. Liu, "A non-linear flow model based on flow translation and its application in the mechanism analysis of water inrush through collapse pillar," Journal of China Coal Society, vol. 42, no. 2, pp. 315-321, 2017.

[13] J. F. Ju, J. L. Xu, Q. S. Li, W. B. Zhu, and X. Z. Wang, "Progress of water-preserved coal mining under water in China," Coal Science and Technology, vol. 46, no. 1, pp. 12-19, 2018.

[14] E. K. Hou, X. Y. Che, T. W. Long, Z. N. Ye, and Q. Wen, "Prediction method of water inrush from ground cracks in shallow buried seams," Journal of China Coal Society, vol. 45, no. 12, pp. 4154-4162, 2020.

[15] Y. J. Zhang, "Principle and key technologies of controlled water mining and practice of fully-mechanized mining under soft sandstone aquifer," Journal of China Coal Society, vol. 45, no. 10, pp. 3380-3388, 2020. 
[16] J. Z. Yang, B. Zhang, X. Y. Fu, Z. Q. Wu, and W. B. Ji, “Formation mechanism of water and sand inrush channel in shallow buried bedrock face," Journal of China Coal Society, vol. 45, no. 12, pp. 4144-4153, 2020.

[17] S. C. Zhang, Y. Y. Li, J. P. Li, W. H. Yang, G. L. Wang, and Z. J. Wen, "Experimental studies on variation characteristics of physical parameters during water and sand burst through mining fractures," Journal of China Coal Society, vol. 45, no. 10 , pp. $3548-3555,2020$.

[18] Y. Xue, T. Teng, F. N. Dang, Z. Ma, S. Wang, and H. Xue, "Productivity analysis of fractured wells in reservoir of hydrogen and carbon based on dual-porosity medium model," International Journal of Hydrogen Energy, vol. 45, no. 39, pp. 20240-20249, 2020.

[19] Z. Z. Cao, P. Xu, Z. H. Li, M. X. Zhang, Y. Zhao, and W. L. Shen, "Joint bearing mechanism of coal pillar and backfilling body in roadway backfilling mining technology," CMC-Computers Materials \& Continua, vol. 54, no. 2, pp. 137-159, 2018.

[20] J. L. Xu, X. Z. Wang, W. T. Liu, and Z. G. Wang, "Effects of primary key stratum location on the height of water flowing fracture zone," Chinese Journal of Rock Mechanics and Engineering, vol. 28, pp. 380-385, 2009.

[21] Y. Xue, F. Gao, Y. N. Gao, X. Liang, Z. Z. Zhang, and Y. Xing, "Thermo-hydro-mechanical coupled mathematical model for controlling the pre- mining coal seam gas extraction with slotted boreholes," International Journal of Mining Science and Technology, vol. 27, no. 3, pp. 473-479, 2017.

[22] M. Faraji, A. Rezagholilou, M. Ghanavati, A. Kadkhodaie, and D. A. Wood, "Breakouts derived from image logs aid the estimation of maximum horizontal stress: a case study from Perth Basin, Western Australia," Advances in Geo-Energy Research, vol. 5, no. 1, pp. 8-24, 2021.

[23] Z. Z. Cao, F. Du, Z. H. Li, Q. T. Wang, P. Xu, and H. X. Lin, "Research on instability mechanism and type of ore pillar based on the fold catastrophe theory," CMES-Computer Modeling in Engineering \& Science, vol. 113, no. 3, pp. 287306, 2017.

[24] Z. H. Li, C. Z. ZhaiI, and L. F. Li, "Experimental study on water inrush mechanism due to floor faults activation in mining above confined aquifer," Journal of Central South University (Science and Technology), vol. 46, no. 5, pp. 1806-1811, 2015.

[25] M. R. Mohammadi, H. Bahmaninia, S. Ansari et al., "Evaluation of asphaltene adsorption on minerals of dolomite and sandstone formations in two and three-phase systems," Advances in Geo-Energy Research, vol. 5, no. 1, pp. 39-52, 2021. 